\title{
Lei de Acesso à Informação como ferramenta de controle social de ações governamentais
}

\author{
The access to information act as a tool for social control of government actions \\ Acceso a la Información como herramienta de control social de las acciones del \\ gobierno \\ Hugo César Peixoto Coutinho ${ }^{1}$ \\ José Luiz Alves²
}

\section{Resumo}

Ter acesso a informações é fundamental para que os cidadãos possam conhecer a gestão da coisa pública e, assim, participar efetivamente das decisões que envolvem os interesses coletivos, através da criação, monitoramento ou controle das ações conduzidas pela administração pública. Os objetivos deste artigo foram discutir a importância da Lei de Acesso à Informação para a construção de uma comunicação pública no Brasil, e analisar a implantação desta lei como ferramenta de controle social das ações governamentais. A partir da revisão bibliográfica de obras de autores que tratam das categorias abordadas, traça um histórico do acesso a informações públicas no Brasil, explica como se deu a comunicação entre o Estado e a sociedade, do início do século XX até os dias atuais, e analisa como a lei que regulamenta esse acesso a informações contribui para o controle social das ações governamentais. Conclui que a Lei de Acesso à Informação consolida uma mudança na relação entre o Estado e a sociedade e fortalece a democracia ao possibilitar maior participação dos cidadãos nos processos decisórios.

Palavras-chave: Comunicação Pública. Acesso à Informação.Transparência Administrativa.Lei № $11.527 / 2011$.

\begin{abstract}
Access to information is essential for citizens to know about management of public affairs and then participating effectively in decisions involving collective interests through creation, monitoring or control of actions taken by government. This article aims both to discuss the importance of the Access to Information Act for creation of public communication in Brazil, and to analyze the implementation of that law as a tool of social control of government actions. From the ideas of authors who deal with that categories, it traces the history of access to public information in Brazil, it also explains how the communication between State and society has worked, from early twentieth century to present days, and it analyzes how the law which regulates the access to information contributes to social control of government actions. The article concludes that the Access to Information Act consolidates a change in the relationship between State and society and strengthens democracy by enabling a greater citizen participation in decision making.
\end{abstract}

Keywords: Public Communication. Access to Information. Administrative Transparency. Act No. 11.527 / 2011.

\footnotetext{
${ }^{1}$ Mestrando do Programa de Pós-Graduação do Mestrado Profissional em Gestão do Desenvolvimento Local Sustentável pela Universidade de Pernambuco (UPE). Especialista em Gestão da Comunicação Empresarial pela Faculdade Frassinetti do Recife (Fafire). Jornalista do campus Vitória de Santo Antão do Instituto Federal de Educação, Ciência e Tecnologia de Pernambuco (IFPE). Brasil, Pernambuco, Vitória de Santo Antão. E-mail: hugocpcoutinho@gmail.com

${ }^{2}$ Doutor em Geografia pela Universidade Federal de Pernambuco (UFPE), Mestre em Geografia e graduado em Ciências Econômicas pela Universidade Federal de Pernambuco (UFPE). Professor adjunto da Faculdade de Ciências da Administração de Pernambuco (FCAP), da Universidade de Pernambuco (UPE). Brasil, Pernambuco, Recife. E-mail: jlzalves@yahoo.com.br
}

Comun. \& Inf., Goiânia, GO, v. 18, n. 1, p. 124-139, jan./jun. 2015 


\section{Resumen}

Tener acceso a la información es esencial para que los ciudadanos conozcan la gestión de los asuntos públicos y así participar efectivamente en las decisiones que afectan a los intereses colectivos a través de la creación, la vigilancia o el control de las acciones tomadas por el gobierno. Los objetivos de este artículo son para discutir la importancia de la Ley de Acceso a la Información para la construcción de una comunicación pública en Brasil, y analizará la aplicación de esta ley como herramienta de control social de las acciones gubernamentales. A partir de la revisión bibliográfica de obras de autores que se ocupan de las categorías de temas, traza una historia de acceso a la información pública en Brasil, explica cómo fue la comunicación entre el Estado y la sociedad, a partir de principios del siglo XX hasta nuestros días, y analiza cómo la ley que regula el acceso a la información contribuyen al control social de las acciones gubernamentales. Concluye que la Ley de Acceso a la Información consolida un cambio en la relación entre el Estado y la sociedad y fortalece la democracia al permitir una mayor participación ciudadana en la toma de decisiones.

Palabras clave: Comunicación Pública. Acceso a la Información. Transparencia Administrativa. Ley $\mathrm{N}^{\circ} 11.527 / 2011$.

\section{INTRODUÇÃO}

partir da redemocratização do Brasil e da promulgação da Constituição Federal de
1988 - que trouxe a garantia de direitos e liberdades antes restritas a parcelas da
sociedade - emergiu-se, aos poucos, a construção de uma nova relação entre Estado, Governo e Sociedade. Cada vez mais, os cidadãos procuram formas de participar das decisões que envolvem os interesses coletivos, seja através da cobrança por mais transparência e eficiência na administração pública, ou através da participação direta, com críticas, sugestões, propostas e monitoramento de políticas públicas. Essas transformações passam, necessariamente, pelo aumento do interesse e pela busca por mais informações a respeito da gestão da coisa pública, o que exigem dos governos uma postura mais horizontalizada para com os cidadãos e a criação de mecanismos legais que assegurem respostas a estas demandas, com base na comunicação pública. Assim, questiona-se: como a Lei $n^{0}$ 12.527, a Lei de Acesso à Informação, pode contribuir para isso? Em que medida ela pode contribuir para uma relação mais democrática entre os governos e a sociedade?

A comunicação pública, no Brasil, é um conceito ainda em construção, porém, vários autores dialogam no sentido de que ela representa a mudança de perspectiva da instituição para o cidadão. Assumir a perspectiva cidadã na comunicação significa alterar o eixo frequentemente voltado para os interesses das instituições e dos seus gestores, ou seja, colocar o cidadão acima de outras esferas, como governamentais, privadas, midiáticas, pessoais ou políticas (DUARTE, 2011). A comunicação pública deve ser entendida como o processo comunicativo entre as instituições públicas e a sociedade, promovendo a troca e o compartilhamento de informações de interesse público (NOVELLI, 2006), o que é um passo inicial para o diálogo entre Estado e sociedade (MAINIERI; RIBEIRO, 2011).

Comun. \& Inf., Goiânia, GO, v. 18, n. 1, p. 124-139, jan./jun. 2015 
A construção de um processo comunicativo com essas características - e motivada pelo interesse público - tem como condição fundamental o acesso a informações voltadas para a cidadania, que constituem uma necessidade apontada pela restauração da democracia e o fortalecimento de novas formas de vivências democráticas (BRANDÃO, 2012). Um dos caminhos para isso é a institucionalização dos instrumentos para o acesso a informações, que se consolida como um direito fundamental de todos os indivíduos expresso na Constituição e protegido por diversos documentos internacionais de direitos humanos. O artigo 19 da Declaração Universal dos Direitos Humanos, o artigo 19 do Pacto Internacional sobre Direitos Civis e Políticos, o artigo 13 da Convenção Interamericana sobre Direitos Humanos, o artigo 9 da Carta Africana sobre os Direitos Humanos e dos Povos e o artigo 10 da Convenção Europeia sobre Direitos Humanos reconhecem o acesso a informações públicas como direito humano fundamental (CANELA; NASCIMENTO, 2009).

Deve-se considerar a importância de mecanismos de controle da Administração Pública, como formas de vigilância e correção de desvios de conduta de agentes públicos, garantindo que a atividade administrativa seja norteada pelo interesse público (MOURA; OLIVEIRA, 2013). Entende-se que o acesso a informações públicas é fundamental a participação efetiva da população - consciente de seus direitos e responsabilidades - e para o interesse desta na gestão de bens e recursos, bem como na criação, execução e monitoramento de políticas voltadas para os interesses de todos, o que resulta em administrações públicas mais eficientes, eficazes e transparentes.

Neste sentido, falar em transparência administrativa pressupõe garantir a participação de atores sociais e o diálogo entre as instituições e a sociedade, além do direito ao acesso a informação como condição para o controle. Ou seja, as ferramentas de promoção da transparência e de acesso a informação possibilitam desde a abertura da administração pública para a participação direta dos cidadãos - democracia participativa - ao monitoramento, avaliação e auxílio na gestão pública - controle social (CARVALHO, 2013).

Sancionada em 2011, a Lei Federal No 12.527, conhecida como Lei de Acesso a Informação (LAI), é um dos principais mecanismos legais criados para se atender a esta demanda, uma vez que regulamenta o artigo $5^{\circ}$, inciso XXXIII, e o artigo 216, $\S 2$ da Constituição Federal de 1988. Sua implementação representa uma mudança de paradigma na gestão pública: do segredo para a transparência, conforme Duarte (2011a). Com a LAI, foi criado um sistema de obtenção de informações de órgãos e entidades públicas dos três Poderes (Executivo, Legislativo e Judiciário), estabelecendo os procedimentos, prazos e responsabilidades dos agentes públicos que não atenderem ao que foi determinado pela Comun. \& Inf., Goiânia, GO, v. 18, n. 1, p. 124-139, jan./jun. 2015 
legislação (CARVALHO, 2013).Ou seja, a lei é uma ferramenta fundamental para o controle social, que envolve questões como elaboração, na deliberação, na implantação, no monitoramento e na avaliação das políticas públicas (MORONI, 2009).

Este artigo teve como objetivos discutir a importância da LAI para a construção de uma comunicação pública no Brasil, baseada no interesse coletivo; e analisar a implantação da lei como ferramenta de controle social das ações governamentais, além das transformações por ela viabilizadas na relação entre a sociedade e o governo. Para isso, a metodologia empregada neste artigo partiu da revisão bibliográfica, como procedimento metodológico, de obras de autores que tratam das categorias analisadas bem como da legislação pertinente disponível em base de dados governamentais e toma como base o método dedutivo.

\section{COMUNICAÇÃO PÚBLICA E O ACESSO A INFORMAÇÕES NO BRASIL}

A noção de comunicação pública - como aquela que tem como foco o cidadão e está embasada não apenas na garantia do acesso à informação e da liberdade de expressão, mas também do diálogo - ainda se confunde com os conceitos de comunicação governamental e comunicação política. Não raro, onde a comunicação deveria atuar como instrumento para a participação ativa da população nas decisões que norteiam o país e fortalecimento da cidadania, ver-se, muitas vezes, a priorização da divulgação de ações - o que atende ao pressuposto da transparência na administração pública - e do convencimento da opinião pública.

É preciso considerar que existe uma tendência de identificar comunicação pública apenas como aquela feita pelos órgãos governamentais. A expressão começou a substituir denominações tradicionalmente utilizadas para designar a comunicação feita pelos governos, como a governamental, política, publicidade governamental ou propaganda política, conforme Brandão (2012). A autora explica que isso não se dá por modismo ou pela procura por novos nomes para práticas já comuns, mas sim, é resultado da necessidade de legitimação de um processo comunicativo - sob a responsabilidade do Estado/Governo - e que não quer ser confundido com a comunicação feita em outros períodos da nossa história política (BRANDÃO, 2012).

De fato, o entendimento sobre comunicação como um serviço público, voltado para o atendimento do interesse coletivo, é construído paulatinamente, o que representa uma evolução, mas ainda parece distante do que é preciso avançar. A ideia é muitas vezes vista como utópica ou ingênua por parte dos que estão no poder. Muitos destes ainda consideram a comunicação um tipo de concessão paternalista para se conseguir apoio, instrumento de persuasão, manipulação, disputa ou manutenção do poder (DUARTE, 2012).

Comun. \& Inf., Goiânia, GO, v. 18, n. 1, p. 124-139, jan./jun. 2015 
Essa ideia equivocada da comunicação entre o governo e seus públicos pode estar relacionada ao fato de que a comunicação governamental no Brasil, historicamente, esteve ligada a ações publicitárias e a ideia do convencimento. $\mathrm{O}$ entendimento de que o governo era o emissor e os cidadãos eram apenas os receptores norteou as ações comunicacionais no setor público por muitas décadas, o que também pode ter contribuído para a cultura do sigilo e a restrição do acesso à informação, observada em diferentes períodos da história política brasileira.

Registros da preocupação em fornecer informações públicas à população através da imprensa datam do início do século XX. O quarto presidente do Brasil, Campos Sales (18981902) contratou os serviços do jornalista Tobias Monteiro, do Jornal do Commercio, do Rio de Janeiro, para escrever os relatos de sua viagem à Europa (MONTEIRO, 2005 apud DUARTE, 2011b). A prática do atendimento à imprensa e da divulgação jornalística no setor público surgiu alguns anos depois, em 1909, com o presidente Nilo Peçanha, que cria um setor para esta finalidade, a Seção de Publicações e Biblioteca para Integrar Serviços de Atendimento, Publicações, Informações e Propagada (DUARTE, 2011b). O objetivo do setor era distribuir informações por meio de notas ou notícias fornecidas à imprensa e a quem as solicitasse, além de editar o Boletim do Ministério (DUARTE, 2011b), atividades bastante semelhantes às realizadas hoje pelas assessorias de imprensa.

Duarte (2011b) explica que o setor passou por mudanças na denominação, mas o regulamento permaneceu sem alterações significativas nas responsabilidades. Mais tarde, no ano de 1915, o setor teve a nomenclatura alterada mais uma vez e apresentou recomendações bastante relevantes. "Em 1915 é definido o nome Serviço de Informações e especificados novos detalhes: 'divulgar, pela imprensa, em notas concisas, mas completas, informações [...] que possam influir no desenvolvimento da produção nacional” (DUARTE, 2011b, p.2).

Nos anos 1930, tornou-se política de governo o controle e a disseminação de informações através dos meios de comunicação em massa, sobretudo através do rádio, estratégico para os governantes. Essa mudança de postura em relação à comunicação governamental começou a se desenhar no Governo Provisório, em 1931, com a estruturação do Departamento Oficial de Propaganda na Imprensa Nacional, que em seguida foi reformulado como Departamento de Propaganda e Difusão Cultural (DPPC) e Departamento Nacional de Propaganda (DUARTE, 2011b). O auge deste modelo aconteceu entre os anos de 1937 e 1945, durante o Estado Novo, quando o rádio e outras ações comunicativas foram adotadas dentro da estratégia de difusão da ideologia o estado Novo e da imagem do presidente Getúlio Vargas, 
função que cabia ao Departamento de Imprensa e Propaganda (DIP) (BARBOSA, 2013). A autora explica que é no auge do estado Novo que o rádio começa a se popularizar.

"Seja porque foi apropriado pelo Estado como possibilidade de estabelecer o diálogo necessário do governo ditatorial com as massas, como estratégia para divulgar em uníssono uma imagem do governo, seja porque reunia todos os ingredientes necessários para estabelecer um diálogo duradouro com o público, seja porque ocorreram transformações tecnológicas e econômicas que tornaram possíveis a sua apropriação de maneira massiva” (BARBOSA, 2013, p. 236).

Simbolizam bem as políticas adotadas nesse período as rigorosas ações de controle dos meios de comunicação, que resultaram no fechamento de vários deles, a criação do noticiário oficial de transmissão diária obrigatória - transmitida até hoje, denominada $\mathrm{A} \mathrm{Voz} \mathrm{do} \mathrm{Brasil}{ }^{3}$ além do aumento significativo da quantidade de emissoras de rádio. Foram inauguradas, no país, 42 emissoras, entre os anos de 1932 e 1937, ano em que foi implantado o Estado Novo, quando havia 62 estações em funcionamento. "Em 1945, quando o regime ditatorial de Vargas chegou ao fim, o número de emissoras de rádio chegava a 111" (GARCIA, 1982 apud BARBOSA, 2013, p.236). Pode-se citar como um dos fatores que contribuíram para a popularização do rádio neste período a penetração deste meio de comunicação. $\mathrm{O}$ ouvinte não precisa passar por um processo de alfabetização, como acontece com a imprensa escrita, por exemplo, e, dessa forma, as informações chegam a todas as classes sociais (CREPALDI, 2009). Diferente da imprensa escrita, com o rádio não há a necessidade de o ouvinte passar por algum tipo de processo de alfabetização, a informação chega diretamente a todas as classes sociais.

Após a popularização do rádio e a modernização da imprensa escrita, na década de 1960, os meios se dirigem ao público indiferenciado, às massas, e essa é a peça-chave para a compreensão dos processos comunicacionais que acontecem no Brasil a partir de então (BARBOSA, 2013). É neste período que acontece uma das principais mudanças na relação entre o governo e a imprensa, e, consequentemente, os cidadãos: o início do regime militar, em 1964. Para Barbosa (2013), a década pode ser caracterizada pela separação da política do conteúdo presente nas publicações, devido à rigorosa censura aos meios de comunicação, sobretudo após o Ato Institucional n. 5, em 1968 (BARBOSA, 2013). A partir do golpe militar

\footnotetext{
${ }^{3}$ O programa A Voz do Brasil entrou no ar em 1935, com o nome de Hora Nacional, e é transmitido até hoje em todas as emissoras de rádio do Brasil, às 19h, no horário oficial de Brasília. De acordo com a EBC Serviços, "o objetivo é levar informação aos cidadãos dos mais distantes pontos do país. O programa tem uma hora de duração. Os primeiros 25 minutos são produzidos pela EBC Serviços e levam aos cidadãos as notícias, de seu interesse, sobre o Poder executivo. Os demais 35 minutos são divididos e de responsabilidade dos Poderes Judiciário e Legislativo. A Voz do Brasil também está no Twitter. Ao longo do dia são postadas informações curtas sobre a pauta e matérias dos programas". Para saber mais sobre o programa A Voz do Brasil, acesse: http://conteudo.ebcservicos.com.br/programas/a-voz-do-brasil
}

Comun. \& Inf., Goiânia, GO, v. 18, n. 1, p. 124-139, jan./jun. 2015 
de 1964, foram intensificados os mecanismos de controle das informações por parte do Estado, que justificava as ações com o argumento de que o Brasil vivia um período politicamente conturbado. A justificativa para a instituição da censura nas diversas dimensões da vida cultural do país revelava o entendimento que se tinha, à época, a respeito do papel da comunicação: não só informar, como orientar a população, sob a tutela do Estado. (BARBOSA, 2013).

A repressão e a restrição a direitos e liberdades revelavam o entendimento de um Estado superior aos cidadãos, responsável por guiá-los e controlá-los em nome do desenvolvimento econômico e contra o que era julgado como ameaça comunista. Era preciso também que o Estado divulgasse suas ações, mas, por outro lado, mantivesse uma imagem positiva, atribuição que foi dada à Assessoria Especial de Relações Públicas (Aerp), em 1968, órgão criado para coordenar a comunicação entre o poder executivo e a sociedade. Dessa forma, "ressaltava seu caráter social e participativo num sistema de decisões centralizadas, em que a participação popular era limitada pelo controle e pela manipulação das informações" (MATOS, 1997 apud MAINIERI; RIBEIRO, 2011, p.51).

Muitos jornais foram ocupados por militares, outros sofreram atos de vandalismo ou foram impedidos de circular, enquanto a censura à imprensa e aos meios de comunicação vigorou entre os anos de 1969 a 1978. (BARBOSA, 2013). As ações comunicativas começaram a ganhar um novo sentindo no ano seguinte, com o início do processo de redemocratização do Brasil, quando é possível perceber mudanças sobre o papel da comunicação na relação entre o Estado e os cidadãos. "É no governo do general Figueiredo (1979-1985) [...] que se cria uma secretaria de comunicação social, a Secom, a qual recebeu como missão preparar o país para uma reabertura política" (MATOS, 1997, apud MAINIERI; RIBEIRO, 2011, p.51).

O período de redemocratização do Brasil, nos anos 1980, foi marcado pelos movimentos a favor de maior participação política dos cidadãos. Nesta época, ganharam força nas organizações - não só as privadas quanto às públicas- as assessorias de imprensa, setores fundamentais para intermediar a relação entre as instituições e a imprensa. A atuação dos assessores como intermediários entre as fontes e a imprensa, com menos espaços para manipulação, convencimento e controle, fez com que as assessorias passassem a ser o ponto de apoio para repórteres e editores, o que ajudou a implantar a cultura da transparência (DUARTE, 2011). De acordo com Duarte (2011b), durante a década de 80, pode-se perceber que as assessorias de imprensa poderiam ser um forte e ativo suporte da sociedade para se obter informações. Outro marco na história da comunicação do Brasil foi a promulgação da Constituição Federal, em 1988. O direito humano à informação, condição fundamental para a 
comunicação pública, está expresso no artigo $5^{\circ}$ e 216, e implícito no artigo 37 da Constituição Federal ${ }^{4}$.

Elizabeth Brandão (2012), em seu artigo intitulado Conceito de Comunicação Pública explica que diante do novo cenário político do Brasil, a comunicação governamental sofreu transformações e adotou o sentido da comunicação pública, aquela que visa prestar informações ao cidadão, o que pode ser percebido desde o governo do presidente Fernando Henrique Cardoso, uma vez que ele afirmava que "a comunicação pública era um tema indissociável do funcionamento da democracia, exercendo o papel de instrumento de uma relação aberta e franca do governo com a população" (BRANDÃO, 2012, p.10). Para a autora, no entanto, é a partir do governo de Luiz Inácio Lula da Silva que a comunicação pública ganha o sentido de informação para a cidadania, passando a ser citada com mais frequência. Este novo entendimento resultou na criação de cursos de atualização para técnicos, além da proposta de criação da função de gestor de Comunicação Pública. Já no segundo ano de mandato foi apresentada uma proposta de Política Nacional de Comunicação, embora as proposições do documento indicassem, na verdade, o objetivo em esclarecer uma política de divulgação (BRANDÃO, 2012).

Apesar de todo avanço registrado, o acesso a informações públicas continuou distante da realidade dos brasileiros durante duas décadas. A regulamentação do inciso XXXIII, que trata do tema, só aconteceu após muitas discussões e cobranças da sociedade civil organizada, 23 anos depois a promulgação da Carta Magna, através da lei $\mathrm{n}^{0} 12.527$, a chamada Lei de Acesso à Informação. Durante este período ocorreu um aumento significativo das leis de acesso à informação adotadas em diferentes partes do mundo, com a missão de fortalecer a transparência dos governos através da disponibilização de informações públicas aos cidadãos (CANELA; NASCIMENTO, 2009).

O Brasil foi um dos últimos países a regulamentar o direito de acesso a informações públicas, constitucionalmente previsto como direito fundamental (CARVALHO, 2013). Ao criar o sistema para obtenção de informações pelo cidadão, estabelecendo procedimentos, prazos e responsabilidades, a lei - promulgada em 18 de novembro de 2011 e que entrou em vigor em 16 de maio de 2012 - a lei pode ser vista como um marco para a comunicação pública

\footnotetext{
${ }^{4}$ A Publicidade é um dos princípios da Administração Pública expressos no Artigo 37 da C.F. O caput do artigo diz: "A administração pública direta e indireta de qualquer dos Poderes da União, dos Estados, do Distrito Federal e dos Municípios obedecerá aos princípios de legalidade, impessoalidade, moralidade, publicidade e efíciência" (BRASIL, 1988). Já o artigo 216 traz em seu $\S 2^{\circ}$ : "Cabem à administração pública, na forma da lei, a gestão da documentação governamental e as providências para franquear sua consulta a quantos dela necessitem” (BRASIL, 1988).
}

Comun. \& Inf., Goiânia, GO, v. 18, n. 1, p. 124-139, jan./jun. 2015 
no país. A LAI estabelece diretrizes para a consolidação do direito fundamental ao acesso à informação, consolidando-o como regra e não como exceção, além do desenvolvimento da cultura da transparência na administração pública e do controle social (CARVALHO, 2013).

\section{A LEI DE ACESSO À INFORMAÇÃO COMO FERRAMENTA DE CONTROLE SOCIAL DAS POLÍTICAS PÚBLICAS}

Com o fim do regime militar e o início do processo de redemocratização do Brasil, bem como em diversos países da América Latina, a sociedade passou a não se contentar mais apenas com a representatividade, com a escolha democrática dos representantes, e passou a buscar os direitos sociais. Essa mudança de postura fica clara na Constituição Brasileira de 1988, conforme explica Silva (2008), no artigo Políticas públicas e intersetorialidade: uma discussão sobre a democratização do Estado. Segundo o autor, a Constituição Brasileira representa o Estado do Bem-estar Social no papel, "um conjunto de direitos sociais são instituídos e o sistema político foi organizado no sentido de garantir a democratização da sociedade através de mecanismos de democracia representativa e de democracia participativa" (p.82).

Durante a década de 1990, o neoliberalismo - com a proposta de redução do papel do Estado - resultou em reformas, não só no Brasil, em mudanças na relação entre o Estado e a sociedade. As mudanças sociais, políticas, institucionais e culturais daquela década indicaram uma sociedade mais consciente de seu papel na construção social (SILVA, 2008), porém questiona-se quais os avanços do Estado diante das experiências de democracia participativa e controle social. Chevallier (apud SILVA, 2008, p.83) afirma: "No Brasil, como em outros países ocidentais, as formas pós-modernas de organização social não são acompanhadas de formas pós-modernas de Estado".

Esse descompasso na relação entre os cidadãos e o Estado exige novas ações da administração pública em busca de participação popular, transparência, eficiência. O Estado precisa ser ágil a fim de produzir serviços públicos com eficiência, precisa ser transparente em todas as ações administrativas, e probo (ABDALA; NASCIMENTO, 2013). Segundo Abdala e Nascimento (2013), “de nada adiantará ser eficiente e transparente se não for probo. A probidade de suas ações é ponto essencial no Estado contemporâneo, o Estado do terceiro milênio" (p.4).

Nesse sentido, têm-se buscado criar mecanismos legais que garantam essas transformações no Estado brasileiro. No ano 2000, registrou-se um grande avanço na 
transparência ativa - ou seja, aquela em que a administração pública divulga informações por iniciativa própria, sem provocação da sociedade - através da Lei Complementar $\mathrm{N}^{\circ} 101$, a chamada Lei de Responsabilidade Fiscal, que no artigo 48 trata da transparência da gestão fiscal $^{5}$. Quase dez anos depois, tornou-se obrigatória a disponibilização em tempo real de informações detalhadas sobre a execução financeira e orçamentária da União, dos Estados, do Distrito Federal e do Município. Essa alteração na redação da Lei de Responsabilidade Fiscal foi feita através da Lei Complementar $\mathrm{N}^{\mathrm{o}} 131$, de 27 de maio de 2009.

Questiona-se sobre a eficácia da divulgação de informações técnicas sobre execução financeira e orçamentária ao grande público. Os usuários, de fato, compreendem como utilizar o grande volume de informações para o controle social? Quanto dessas informações são utilizadas de maneira que possam embasar as decisões dos cidadãos? Apenas essa divulgação espontânea é o suficiente para falarmos de transparência e maior participação da sociedade nos processos decisórios de políticas públicas?

A Lei $\mathrm{N}^{0} 12.527$ traz avanços significativos neste sentido, ao regulamentar as obrigações das instituições quanto à transparência ativa, além dos procedimentos e prazos para divulgação de informações solicitadas pelos próprios cidadãos. A LAI prevê a gestão transparente da informação, permitindo o acesso amplo, regulamentando os processos para o acesso e vedando a negação a este (MOURA; OLIVEIRA, 2013).

Diante de toda produção normativa existente, a lei traz avanços no sentido da consolidação da transparência ativa, inovando ao estabelecer um conjunto mínimo de informações a serem disponibilizadas obrigatoriamente nos sítios eletrônicos de todos os órgãos e entidades públicas de todos os poderes e de todas as esferas do governo. (CARVALHO, 2013). Estão subordinados à lei os órgãos e entidades públicas dos poderes Executivo, Legislativo e Judiciário, em todos os níveis de governo (federal, estadual, distrital e municipal), além das Cortes de Conta, do Ministério Público, as autarquias, as fundações públicas, as empresas públicas, as sociedades de economia mista e demais entidades controladas direta ou indiretamente pela União, Estados, Distrito Federal e Municípios (BRASIL, 2011). Além destes, também estão sujeitas à lei as entidades privadas que recebam recursos públicos ${ }^{6}$.

\footnotetext{
5 “Art. 48. São instrumentos de transparência da gestão fiscal, aos quais será dada ampla divulgação, inclusive em meios eletrônicos de acesso público: os planos, orçamentos e leis de diretrizes orçamentárias; as prestações de contas e o respectivo parecer prévio; o Relatório Resumido da Execução Orçamentária e o Relatório de Gestão Fiscal; e as versões simplificadas desses documentos" (BRASIL, 2000).

${ }^{6} \mathrm{O}$ artigo $2^{\circ}$ da Lei 12.527 afirma: "Aplicam-se as disposições desta Lei, no que couber, às entidades privadas sem fins lucrativos que recebam, para realização de ações de interesse público, recursos públicos diretamente do orçamento ou mediante subvenções sociais, contrato de gestão, termo de parceria, convênios, acordo, ajustes ou outros instrumentos congêneres" (BRASIL, 2011).
}

Comun. \& Inf., Goiânia, GO, v. 18, n. 1, p. 124-139, jan./jun. 2015 
Quanto à transparência passiva, ou seja, a divulgação de informações solicitadas pelo usuário, um dos primeiros aspectos a serem considerados é o entendimento de que a informação produzida, guardada, organizada e gerenciada pelo Estado é um bem público, devendo a restrição de acesso ser tratada como exceção (CGU, 2011). Assim, os cidadãos que solicitarem informações desses órgãos e entidades não deverão ficar sem respostas e terão o atendimento garantido dentro dos prazos. Esses procedimentos - cujo objetivo é garantir o direito fundamental ao acesso à informação - tomam como base os princípios da administração pública e as diretrizes expressas no artigo $3^{\circ}$, que são:

"I - observância da publicidade como preceito geral e do sigilo como exceção; II - divulgação de informações de interesse público, independentemente de solicitações; III - utilização de meios de comunicação viabilizados pela tecnologia da informação; IV - fomento ao desenvolvimento da cultura de transparência na administração pública; V - desenvolvimento do controle social da administração pública" (BRASIL, 2011).

A lei garante que os cidadãos possam receber informações de interesse pessoal ou coletivo, e o pedido não precisa ser justificado - basta apenas conter a identificação do requerente e a especificação da informação solicitada. Os pedidos são gratuitos, salvo em caso de cópias de documentos. A lei também cria o dever de órgãos e entidades públicas de implantar o Serviço de Informações ao Cidadão (SIC), uma ferramenta de comunicação por meio do qual o cidadão pode protocolar a solicitação de acesso à informação e é atendido e orientado, além de receber informações sobre o andamento do processo (CARVAHO, 2013). Sobre isso, tratam os artigos $8^{\circ}$ e $9^{\circ}$.

O caput do artigo $8^{\circ}$ é enfático ao afirmar que é dever dos órgãos e entidades públicas "promover, independentemente de requerimentos, a divulgação em local de fácil acesso, no âmbito de suas competências, de informações de interesse coletivo ou geral por eles produzidas ou custodiadas" (BRASIL, 2011). E entre as informações de divulgação obrigatória expressas nos incisos estão desde registro das competências e estrutura organizacional, endereços, telefones das unidades e horários de atendimento ao público, até informações concernentes a procedimentos licitatórios, inclusive os respectivos editais e resultados, bem como a todos os contratos celebrados ${ }^{7}$.

\footnotetext{
${ }^{7}$ Artigo $8^{\circ}, \S 1^{\circ}$ : "Na divulgação das informações a que se refere o caput, deverão constar, no mínimo: I - registro das competências e estrutura organizacional, endereços e telefones das respectivas unidades e horários de atendimento ao público; II - registros de quaisquer repasses ou transferências de recursos financeiros; III - registros das despesas; IV - informações concernentes a procedimentos licitatórios, inclusive os respectivos editais e resultados, bem como a todos os contratos celebrados; V - dados gerais para o acompanhamento de programas, ações, projetos e obras de órgãos e entidades; e VI - respostas a perguntas mais frequentes da sociedade" (BRASIL, 2011).
}

Comun. \& Inf., Goiânia, GO, v. 18, n. 1, p. 124-139, jan./jun. 2015 
Já o artigo $9^{\circ}$ cria o SIC nos órgãos e entidades do poder público, uma ferramenta inovadora para garantir o acesso à informação. De acordo com a lei, esse serviço deve ser oferecido em locais com condições apropriadas para: “a) atender e orientar o público quanto ao acesso a informações; b) informar sobre a tramitação de documentos nas suas respectivas unidades; c) protocolizar documentos e requerimentos de acesso a informações" (BRASIL, 2011). As informações solicitadas devem ser repassadas aos solicitantes imediatamente, mas caso não estejam disponíveis, a instituição tem 20 dias para disponibilizá-las, prazo que pode ser prorrogado por mais dez dias. Caso a informação esteja sujeita a um dos tipos de sigilo, "é direito de o requerente obter o inteiro teor de decisão de negativa de acesso, por certidão ou cópia” (BRASIL, 2011).

Diante da negativa de acesso, a ferramenta disponível ao cidadão é a possibilidade de interpor recursos contra a decisão no prazo máximo de dez dias, a contar da data da ciência. A CGU (2011) resume:

"O cidadão pode interpor recurso à autoridade hierarquicamente superior àquela que emitiu a decisão. Persistindo a negativa, o cidadão poderá recorrer ao Ministério de Estado da área ou, em caso de descumprimento de procedimentos e prazos da Lei 12.527, à CGU. Em última instância, caberá recurso à Comissão Mista de Reavaliação de Informações" (CGU, 2011, p. $15)$.

As exceções para as regras de acesso se dão quanto às informações pessoais e aquelas classificadas pelas autoridades como sigilosas. A lei é bastante clara quanto a quem pode classificar essas informações ${ }^{8}-$ o que evita que qualquer agente público sem interesse em disponibilizar a informação a negue para o requerente - e quando elas podem ser dadas como sigilosas: "quando considerada imprescindível à segurança da sociedade (à vida, segurança ou saúde da população) ou do Estado (soberania nacional, relações internacionais, atividades de inteligência" (CGU, 2011, p.16).

Outro aspecto relevante é que a lei prevê a responsabilização do servidor nos casos de seu descumprimento, conforme explica a CGU:

\footnotetext{
"Recusar-se a fornecer informação requerida nos termos da Lei, destruir ou alterar documentos ou impor sigilo para obtenção de proveito pessoal, por exemplo, são consideradas condutas ilícitas, podendo caracterizar infração ou improbidade administrativa" (2011, p.17).
}

\footnotetext{
${ }^{8}$ Sobre os Procedimentos de Classificação, Reclassificação e Desclassificação das informações públicas, ver os artigos 27, 28, 29 e 30 da Lei 12.527/2011.
}

Comun. \& Inf., Goiânia, GO, v. 18, n. 1, p. 124-139, jan./jun. 2015 
Esses recursos auxiliam os cidadãos a conhecerem e fiscalizarem a gestão pública, contribuindo para a transparência, o combate à corrupção, e possibilitando a todos maiores oportunidades de participação em todos os processos decisórios, contribuindo assim para o controle social. Observa-se que o controle social não quer dizer apenas a consulta ao Estado ou a questão do acesso à participação, mas diz respeito ao cidadão participar do destino da nação (MORONI, 2009). De acordo com Moroni (2009), o direito humano à participação faz parte de uma concepção política que vai além da representatividade, ou seja, de que a sociedade deve participar da vida pública além do direito à representação, já consolidado. $\mathrm{O}$ autor afirma que, ao falar em controle social, são trabalhadas cinco questões que o estruturam, que são o direito de participar na elaboração, na deliberação, na implantação, no monitoramento e na avaliação das políticas públicas. "Há um outro ponto: a questão do orçamento. Quais são os recursos de que determinada política pública dispõe? Enfim, quando se fala em controle social, subentendese todo esse conjunto de pontos, de direitos." (MORONI, 2009, p. 40).

Na opinião de Carvalho (2013), a participação popular na gestão e no controle social da administração pública são inerentes ao Estado Democrático de Direito. A transparência nas atividades do Estado é uma condição necessária para que as pessoas conheçam a gestão da coisa pública e, assim, possam participar efetivamente (CARVALHO, 2013).

\section{CONSIDERAÇÕES FINAIS}

A implementação da LAI, embora tardia, acontece em consonância com uma tendência mundial da década de 1980 e que ganhou força nos últimos vinte anos: a busca do cidadão por transparência na gestão pública e por maior participação nos processos decisórios. Ao regulamentar o artigo $5^{\circ}$, inciso XXXIII, e o artigo 216, § 2 da Constituição Federal de 1988, a lei contribui significativamente para a consolidação da comunicação pública que vem sendo construída, e que, aos poucos, revela a mudança para uma perspectiva cidadã, em detrimento da postura frequentemente voltada para as instituições e seus gestores, conforme explica Duarte (2011a).

Os elementos criados pela lei possibilitam a aproximação e o diálogo entre instituições e sociedade, consolidando vivências democráticas, uma vez que dá condições de participação da população na criação, na execução, na fiscalização e no controle de ações, programas e projetos desenvolvidos pelo poder público. Para que isso seja possível, é imprescindível que os cidadãos tenham à disposição ferramentas que possam garantir-lhes o acesso a informações públicas e, neste sentido, a LAI apresenta-se como um passo significativo, podendo ser considerada um marco na administração pública no Brasil.

Comun. \& Inf., Goiânia, GO, v. 18, n. 1, p. 124-139, jan./jun. 2015 
A história política do país mostra que essa conquista é recente e resultante de diversas lutas da sociedade civil organizada. Conforme explanado neste artigo, por diversos momentos da nossa história as informações públicas estiveram inacessíveis, e era o Estado quem exercia o controle não só sobre elas, mas sobre os meios de comunicação e até sobre os cidadãos. Percebem-se ainda avanços relevantes no tocante à comunicação pública, em que o cidadão é o protagonista e não mais, apenas, o receptor das informações dos governos.

Com os avanços conquistados, tem-se maior transparência ativa e passiva, e os cidadãos, bem informados, tem melhores condições para construir o conhecimento e assumir uma postura mais crítica em relação aos três poderes. Assim, a sociedade tem, por um lado, os meios de organização coletiva, através de conselhos, fóruns e conferências - onde a comunicação se realiza e os cidadãos são os sujeitos - e, por outro lado, as ferramentas que precisa para ter acesso à informação pública produzida, guardada, organizada e gerenciada pelo Estado.

Assim, ao regulamentar o acesso a informações, um direito fundamental do cidadão, o Brasil consolida uma mudança construída aos poucos, a partir das garantidas expressas na Constituição Federal. É consenso afirmar que as Leis Complementares N ${ }^{o} 101$ e No 131 foram fundamentais para fortalecer a democracia participativa no Brasil e estreitaram as relações entre o Estado e os cidadãos. Porém, a partir da aprovação da Lei de Acesso à Informação um grande passo foi dado para a ampliação da participação popular e, consequentemente, o controle social das políticas públicas.

Após aproximadamente três anos em vigor, é preciso aprofundar os estudos no sentido de analisar as consequências da LAI na relação entre a sociedade e as instituições. Assim, este artigo sugere a realização de pesquisa que avalie questões como: a percepção dos gestores a respeito da lei; os impactos da lei nas instituições; e o quanto a lei é conhecida e como é utilizada pelos cidadãos.

\section{REFERÊNCIAS}

ABDALA, J.; NASCIMENTO, M. R. Lei de Acesso à Informação: um instrumento de controle social da Administração Pública. 2012. 18p. Trabalho de Conclusão de Curso (Pós-graduação em Gestão Pública)-Associação dos Municípios da Microrregião Baixa Mogiana (AMOG) e Instituto Federal do Sul de Minas Gerais, Minas Gerais, 2012.

BARBOSA, Marinalva. História da comunicação no brasil. Petrópolis: Vozes, 2013.

BRANDÃO, E. P. Conceito de comunicação pública. In: DUARTE, Jorge (Org). Comunicação pública: estado, mercado, sociedade e interesse público. 3.ed. São Paulo: Atlas, 2012. p. 1-33.

Comun. \& Inf., Goiânia, GO, v. 18, n. 1, p. 124-139, jan./jun. 2015 
BRASIL. Constituição (1988). Constituição da República Federativa do Brasil de 1988. Diário Oficial [da] República Federativa do Brasil, Poder Legislativo, Brasília, DF, 5 out. 1988. Disponível em: <http://www.planalto.gov.br/ccivil_03/constituicao/constituicaocompilado.htm>. Acesso em: 15 set. 2014.

BRASIL. Lei Complementar n. 101, de 4 de maio de 2000. Estabelece normas de finanças públicas voltadas para a responsabilidade na gestão fiscal e dá outras providências. Diário Oficial [da] República Federativa do Brasil, Poder Legislativo, Brasília, DF, 24 maio 2000. Disponível em: $<$ http://www.planalto.gov.br/ccivil_03/leis/lcp/lcp101.htm>. Acesso em: 15 dez. 2014.

BRASIL. Lei Complementar n. 131, de 27 de maio de 2009. Diário Oficial [da] República Federativa do Brasil, Poder Legislativo, Brasília, DF, 27 maio 2009. Disponível em: $<$ http://www.planalto.gov.br/ccivil_03/leis/lcp/lcp131.htm>. Acesso em: 16 dez. 2014.

BRASIL. Lei n. 12.527, de 18 de novembro de 2011. Diário Oficial [da] República Federativa do Brasil, Poder Legislativo, Brasília, DF, 18 nov. 2011.Disponível em: < http://www.planalto.gov.br/ccivil_03/_ato2011-2014/2011/lei/112527.htm>. Acesso em: 2 set. 2014.

CANELA, G.; NASCIMENTO, S (Orgs.). Acesso à informação e controle social das políticas. Brasília: ANDI; Artigo 19, 2009. Disponível em: < http://www.andi.org.br/politicas-decomunicacao/publicacao/acesso-a-informacao-e-controle-social-das-politicas-publicas $>$. Acesso em: 2 jun. 2014.

CARVALHO, J. L. B. V. B. A Lei de Acesso à Informação no contexto evolutivo do controle social da administração pública. 2013. 139 f. Monografia (Bacharelado em Direito) - Faculdade de Direito, Universidade de Brasília, Brasília. Disponível em: $<$ http://bdm.unb.br/bitstream/10483/6812/1/2013_JulianaLopesBarrosoVillasBoasCarvalho.pdf $>$. Acesso em: 20 dez. 2014.

CONTROLADORIA GERAL DA UNIÃO. Acesso à informação pública: uma introdução à Lei 12.527, de 18 de novembro de 2011. Brasília, DF, [s.n.], 2011. Disponível em:

$<$ http://www.cgu.gov.br/acessoainformacao/materiais-interesse/cartilhaacessoainformacao.pdf $>$. Acesso em: 12 mai. 2014.

DUARTE, J. Sobre a emergência do (s) conceito(s) de comunicação pública. In: KUNSCH, Margaria M. Krohling (Org). Comunicação pública, sociedade e cidadania. São Caetano do Sul: Difusão Editora, 2011a.

DUARTE, J. Assessoria de imprensa no Brasil. 2011b. [S.1.: s.n.]. Disponível em: $<$ http://twileshare.com/uploads/Assessoria_de_Imprensa_no_Brasil_2011.pdf $>$. Acesso em: $20 \mathrm{dez}$. 2014.

DUARTE, J. Instrumentos de comunicação pública. In: DUARTE, Jorge (Org). Comunicação Pública: Estado, mercado, sociedade e interesse público. 3.ed. São Paulo: Atlas, 2012.

MAINIERI, T.; RIBEIRO, E. M. A.O. A comunicação pública como processo para o exercício da cidadania: o papel das mídias sociais na sociedade democrática. Organicom: Revista Brasileira de Comunicação Organizacional e Relações Públicas, São Paulo, ano 8, n.14, p.50-61, 2011. Disponível em: $<$ http://revistaorganicom.org.br/sistema/index.php/organicom/article/view/339>. Acesso em: 5 jun. 2014.

MORONI, J. A. Os cinco eixos do controle social. In: CANELA, G.; NASCIMENTO, S. Acesso à informação e controle social das políticas. Brasília: ANDI; Artigo 19, 2009. Disponível em: $<$ http://www.acessoainformacao.gov.br/acessoainformacaogov/publicacoes/Acesso-a- informacao-econtrole-social-das-politicas-publicas.pdf $>$. Acesso em: 2 Jun. 2014.

Comun. \& Inf., Goiânia, GO, v. 18, n. 1, p. 124-139, jan./jun. 2015 
MOURA, E.A. C; OLIVEIRA, L. R. Controle social da administração pública, transparência administrativa e Lei de Acesso à Informação. In: CONGRESSO BRASILEIRO DE PROCESSO COLETIVO E CIDADANIA, 1., 2013, Ribeirão Preto. Anais... Ribeirão Preto: Universidade de Ribeirão Preto, 2013. p. 53-58. Disponível em:

$<$ http://www9.unaerp.br/revistas/index.php/cbpcc/article/view/262>. Acesso em: 21 dez. 2014.

NOVELLI, A. L. O papel institucional da comunicação pública para o sucesso da governança.

Organicom: Revista Brasileira de Comunicação Organizacional e Relações Públicas, São Paulo, ano 3, n. 4. p.75-89, 2006. Disponível em:

$<$ http://revistaorganicom.org.br/sistema/index.php/organicom/article/view/56/190>. Acesso em: 21

dez. 2014.

SILVA, G. T. Políticas públicas e intersetorialidade: uma discussão sobre a democratização do Estado. Cadernos Metrópole, São Paulo, n.19, p. 81-97, 2008.Disponível em:

$<$ http://revistas.pucsp.br/index.php/metropole/article/view/8711>. Acesso em: 14 set. 2014.

Recebido em: $12 / 02 / 2015$

Aceito em: 04/04/2014

Publicado em: 15/06/2015 